\title{
The Effect of Hafnium Content and Cycling under an Applied Axial Stress on the Creep and Martensite Strain of NiTi Based Shape Memory Alloy Wires
}

\author{
P.E. Thoma, C. Zhang*, J.J. Boehm and R.H. Zee* \\ Johnson Controls Inc., Central Research A-37, 1701 West Civic Drive, Milwaukee, WI 53209, U.S.A. \\ * Auburn University, Materials Engineering Department, MTL Program, 202 Ross Hall, Auburn, \\ AL 36849, U.S.A.
}

\begin{abstract}
The effect of cycling under an applied axial stress of $206.8 \mathrm{MPa}$ on the creep and martensite strain of a Ti rich NiTi shape memory alloy (SMA) and two ternary SMAs, having the compositions Ni49Ti51-xHfx with 1 at.\% and 3 at.\% Hf, is investigated. The wires used in this investigation have approximately $40 \%$ cold work (reduction in area) and a heat treatment (HT) temperature ranging from $300^{\circ} \mathrm{C}$ to $600^{\circ} \mathrm{C}$. The results show, that for a given HT and an applied axial stress of $206.8 \mathrm{MPa}$, creep decreases with increasing Hf content. For the three alloys evaluated, creep increases with increasing HT temperature. Stress induced martensite strain during the transformation of austenite to martensite is least when the HT temperature is lowest $\left(300^{\circ} \mathrm{C}\right)$, and for the three alloys heat treated at $300^{\circ} \mathrm{C}$, the martensite strain decreases with increasing $\mathrm{Hf}$ content. For the SMAs heat treated at the highest HT temperature $\left(600^{\circ} \mathrm{C}\right)$, the martensite strain decreases with an increasing number of transformation cycles, and the martensite strain decreases least for the SMA with 3 at.\% Hf. Although the martensite strain is stable from 1 to 100 transformation cycles for the three SMAs heat treated at $300^{\circ} \mathrm{C}$, the SMA with 3 at. \% Hf retains stress induced martensite strain stability the best as the HT temperature increases.
\end{abstract}

\section{INTRODUCTION}

Kleinherenbrink and Beyer [1] suggested that the addition of third and fourth elements to NiTi alloys can be used to control transformation temperatures (TTs). They also mentioned that $\mathrm{Zr}$, when added to a NiTi alloy, should increase the TTs of the alloy. The work of Kleinherenbrink and Beyer [1] provided the impetus to AbuJudom et al. [2] and Angst et al. [3] to investigate the influence of Hf substitution for Ti in NiTi-based alloys on TTs. AbuJudom et al. [2] and Angst et al. [3] showed that Hf, when substituted for $\mathrm{Ti}$, has a significant influence on increasing the TTs of NiTi-based alloys when the Hf content is $>8$ at. $\%$. Mulder et al. [4], Mulder [5], and Tuominen [6] provided additional information on the influence of Hf on the microstructure and transformation characteristics of NiTi-based alloys. Russell and Sczerzenie [7] showed the feasibility of the NiTiHf system from cost and processing points of view. Zhang et al. [8,9] and Zhang [10] investigated the effects of thermal-mechanical processing and low Hf contents $(0,1$ and 3 at. \%) on the transformation of austenite (A) to martensite $(\mathbf{M})$ and the austenite to R-Phase $(\mathbf{A} \rightarrow \mathbf{R})$ and $\mathbf{R} \rightarrow \mathbf{A}$ transformations.

This investigation is a continuation of the published work of Zhang et al. [8,9] and Zhang [10]. The objective of this work is to show the influence of low Hf content $(0,1$ and 3 at.\%), thermal-mechanical processing, and cycling under an applied axial stress on the creep and martensite strain of NiTi-based wires.

\section{EXPERIMENTAL PROCEDURES}

Thermal cycling between $\mathbf{A}$ and $\mathbf{M}$ under an applied axial tensile stress of $206.8 \mathrm{MPa}$ was performed on SMA wires having the compositions Ni49Ti51, Ni49Ti50Hf 1 , and Ni49Ti48Hf3. The binary NiTi alloy, with an annealed $\left(700^{\circ} \mathrm{C} \mathrm{HT}\right.$ ) austenite finish temperature (Af) of $116^{\circ} \mathrm{C}$, was obtained as a wire from Furukawa Electric Co., Ltd. The Hf containing ternary alloys were made by vacuum arc melting into a cigar shape ingot followed by homogenization at $1000^{\circ} \mathrm{C}$ for 94.5 hours in vacuum. The Hf containing ingots were centerless ground into a rod having a uniform diameter. The rods were encased in steel, hot rolled at $900^{\circ} \mathrm{C}$ and then cold drawn into wires. The annealed $\left(700^{\circ} \mathrm{C} \mathrm{HT}\right)$ Af is $121^{\circ} \mathrm{C}$ for the Ni49TisoHf 1 alloy and is 
$132^{\circ} \mathrm{C}$ for the $\mathrm{Ni} 49 \mathrm{Ti} 48 \mathrm{Hf} 3$ alloy. The cold drawn wires were repeatedly vacuum annealed at $700^{\circ} \mathrm{C}$ for one hour to permit continued cold drawing to smaller diameters. Annealed wire was then cold drawn to a diameter $(0.0366 \mathrm{~cm})$ to provide a reduction in area of about $40 \%$. The wires, having about $40 \%$ cold work (CW) and a length of $15 \mathrm{~cm}$, were heat treated in a straight position at temperatures between $300^{\circ} \mathrm{C}$ and $600^{\circ} \mathrm{C}$ for one hour in an argon atmosphere (Table I).

Table I: SMA compositions, cold work, and HT temperatures used in this investigation.

\begin{tabular}{|l|c|c|c|}
\hline Composition & Af, $^{\circ} \mathrm{C}$ & Cold Work, \% & Heat Treatment Temperature, ${ }^{\circ} \mathrm{C}$ \\
\hline Ni49Tis1 & 116 & 39.8 & 300,350 \\
\hline Ni49TisoHf 1 & 121 & 39.1 & 400,450 \\
\hline Ni49Ti48Hf3 & 132 & 39.1 & 500,600 \\
\hline
\end{tabular}

Temperature - strain curves (Ms curves), such as shown in Figure 1, were used to determine the creep and $\mathbf{M}$ strain properties of the alloys investigated. To measure the temperature of the test wire, a thermocouple was brazed to a stainless steel wire having a diameter the same as the test wire, and placed in close proximity to the test wire. A linear variable differential transformer (LVDT) was mounted below a hole in the bottom of the test cabinet to measure the change in length of the test wire as a function of temperature. The test wire was terminated with crimped connectors and mounted to a support of the test cabinet. An Invar extension rod was connected to the bottom test wire termination, and passed through the hole in the bottom of the test cabinet. An aluminum extension rod was used outside of the cabinet to make connection to the core of the LVDT. The required additional weight, to obtain an applied axial tensile stress of $206.8 \mathrm{MPa}(30,000 \mathrm{psi})$ in the test wire, was placed in a pan attached to an extension rod below the core of the LVDT. The weight was applied to the heated SMA wire in the A phase at the beginning of the first Ms cycle. The test cabinet used in this study was a Delta - Model 9039 temperature cabinet with a programmed heating and cooling rate of $5^{\circ} \mathrm{C} /$ minute, and a temperature test range from $160^{\circ} \mathrm{C}$ to $-60^{\circ} \mathrm{C}$ for all test wires except wires heat treated at $600^{\circ} \mathrm{C}$. A temperature test range from $210^{\circ} \mathrm{C}$ to $-60^{\circ} \mathrm{C}$ was used for the test wires with a $600^{\circ} \mathrm{C}$ HT because of their higher A TT. Liquid nitrogen was used to cool the test cabinet during the cooling portion of the Ms cycle. All test wires were cycled 100 times, and the Ms cycle started and ended at high temperature with the test wire in the $\mathbf{A}$ phase.

\section{TEST RESULTS}

The first and second Ms curves for the Ni49TisoHf 1 alloy wire having $39.1 \% \mathrm{CW}$ and $500^{\circ} \mathrm{C} \mathrm{HT}$ with an applied axial tensile stress of $206.8 \mathrm{MPa}$ are shown in Figure 1. These curves are typical of all curves obtained in this investigation, and are used to obtain data to calculate the creep and M strain in the SMA wires.

Creep in Ni49Tis1, Ni49TisoHf 1 , and Ni49Ti48Hf3 alloy wires, which increases with an increasing number of transformation cycles, is shown in Figures 2, 3, and 4 respectively. Creep is calculated using Equation 1 (adjacent Figure 4), and is expressed as a percent of the starting length of the wire in the $\mathbf{A}$ phase. For a specific composition and a specific number of transformation cycles, creep generally increases with increasing HT temperature. For a specific number. of transformation cycles and a specific HT temperature, creep increases with decreasing Hf content.

$M$ strain in Ni49Ti51, Ni49Ti50Hf1, and Ni49Ti48Hf3 alloy wires is shown in Figures 5, 6, and 7 respectively. Equation 2 (adjacent Figure 7) is used to calculate $\mathbf{M}$ strain, which is expressed as a percent of the length of the wire in the A phase at the beginning of a specific cycle. The trends observed for the $\mathbf{M}$ strain are more complex than the trends observed for creep. For the three compositions having the highest $\mathrm{HT}$ temperature $\left(600^{\circ} \mathrm{C}\right), \mathbf{M}$ strain decreases with an increasing number of transformation cycles. Of the alloys heat treated at $600^{\circ} \mathrm{C}$, the composition with 3 at. \% Hf has the least decrease in $M$ strain during transformation cycling. The greatest decrease in $M$ strain during transformation cycling occurs in the Ni49Tis1 alloy $\left(0\right.$ at.\% $\mathrm{Hf}$ ) heat treated at high temperatures $\left(450,500\right.$, and $\left.600^{\circ} \mathrm{C}\right)$, and the least decrease in M strain, of the three alloys heat treated at high temperature, occurs in the Ni 49Ti48Hf3 alloy. When heat treated at the lowest $\mathrm{HT}$ temperature $\left(300^{\circ} \mathrm{C}\right.$ ), there is little change in $\mathbf{M}$ strain of the three compositions with an increasing number of transformation cycles. At the start of cycling (cycle 1), $\mathbf{M}$ strain of each composition generally increases with increasing HT temperature. At the start of cycling (cycle 1) for a specific HT, M strain decreases with increasing Hf content. 


\section{DISCUSSION OF RESULTS}

When a SMA wire has an applied axial tensile stress and is cooled in the $\mathbf{A}$ phase, $\mathbf{M}$ is stress induced over a specific temperature range and the wire increases in length as the transformation to $\mathbf{M}$ occurs. When a wire with an applied axial tensile stress is cycled between a high and low temperature and the $\mathbf{A} \rightarrow \mathbf{M} \rightarrow \mathbf{A}$ transformations occur, the length of the wire increases when the SMA transforms from $\mathbf{A}$ to $\mathbf{M}$ and decreases when the SMA transforms back to $\mathbf{A}$. Figure 1 shows the first and second transformation cycles of a Ni49TisoHf 1 alloy wire with $39.1 \% \mathrm{CW}$ and $\mathrm{HT}$ at $500^{\circ} \mathrm{C}$. Creep, which occurs during transformation cycling, and $\mathbf{M}$ strain are determined from the length of the SMA wire in the $\mathbf{A}$ and $M$ phases.

Thoma et al. [11] show that the TTs and creep of a binary NiTi SMA are strongly affected by thermalmechanical processing, applied stress, and cycling under an applied stress. The creep results of this study show the same trends as shown by Thoma et al. [11]. Creep in Ni49Ti51, Ni49Ti50Hf 1, and Ni49Ti48Hf3 alloy wires increases with an increasing number of transformation cycles. For a specific composition and a specific number of transformation cycles, creep generally increases with increasing HT temperature (Figures 2,3, and 4). Creep is plastic flow of the SMA and results in a wire having a longer length and smaller diameter. During creep due to transformation cycling, defects, such as dislocations, are introduced, move and reorganize. In SMA wires, especially with a low dislocation density, additional dislocations are introduced during transformation cycling. Creep is least in the SMA wires with low HT temperature because of their high dislocation density due to retention of dislocations introduced during cold working. A high defect density promotes a pinned structure that is resistant to creep. Creep is greatest in the cold worked SMA wires having a high HT temperature due to removal of dislocations during HT. For a specific number of transformation cycles and a specific thermal-mechanical processing condition (CW and HT), creep decreases with increasing Hf content. As shown in Figures 2,3, and 4, the presence of Hf results in a retention of the cold worked structure to higher HT temperatures. Without Hf (Figure 2), the dependence of creep on $\mathrm{HT}$ temperature starts at $300^{\circ} \mathrm{C}$, whereas $\mathrm{HT}$ has little effect on creep until above $350^{\circ} \mathrm{C}$ in the alloy with 1 at.\% Hf. Similarly, creep in the SMA with 3 at.\% Hf remains independent of HT until an even higher HT temperature above $450^{\circ} \mathrm{C}$. The improvement in creep properties with increasing $\mathrm{Hf}$ content is attributed to the presence of $\mathrm{Hf}$. In these alloys, $\mathrm{Hf}$ is substituted for $\mathrm{Ti}$, and since the covalent radius of $\mathrm{Hf}$

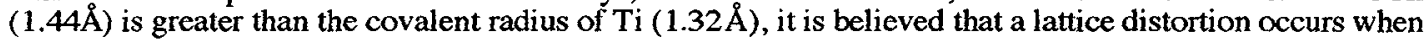
$\mathrm{Hf}$ is substituted for $\mathrm{Ti}$. The interaction of dislocations and other defects in the distorted lattice is probably different than that in the binary NiTi lattice, thereby modifying the tendency to plastically flow (creep). It is conceivable that electronic interactions in ternary NiTiHf alloys, between $\mathrm{Hf}-\mathrm{Ti}$ and $\mathrm{Hf}-\mathrm{Ni}$, also influence the interactions with dislocations and other defects, thereby improving the creep properties of NiTi alloys containing $\mathrm{Hf}$.

$M$ strain is also influenced by dislocation density. When a SMA wire is cold drawn and heat treated at a low temperature $\left(300^{\circ} \mathrm{C}\right)$, dislocations, which are retained in the alloy, provide a stable structure in which the $\mathbf{M}$ strain does not change when cycled under an applied axial stress. However, when a SMA wire is cold drawn and heat treated at a high temperature $\left(600^{\circ} \mathrm{C}\right)$, excess dislocations are removed and complete

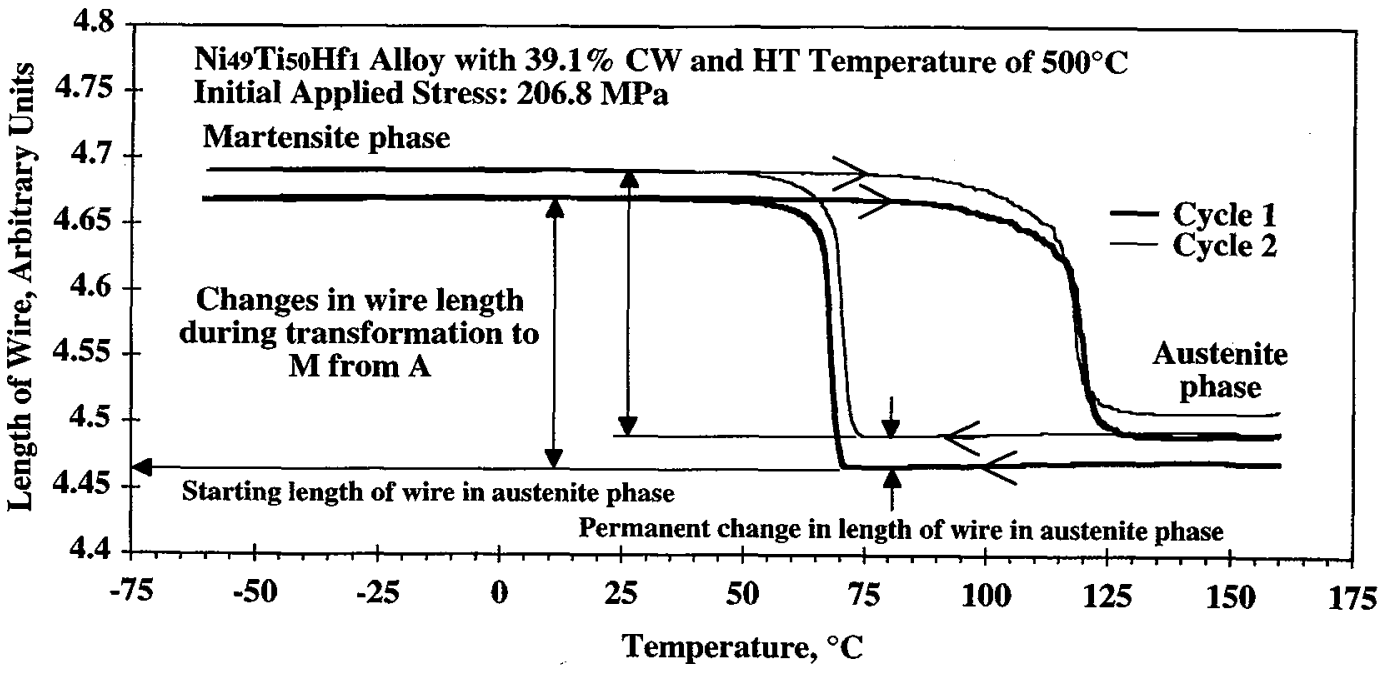

Figure 1: Austenite to martensite to austenite transformation cycles for Ni49Ti50Hfl alloy (Ms curves). 
recrystallization occurs. A SMA wire with a low dislocation density has a high $\mathbf{M}$ strain during the first transformation cycle. The binary NiTi wire, with $39.8 \% \mathrm{CW}, 600^{\circ} \mathrm{C} \mathrm{HT}$, and an applied stress of 206.8 $\mathrm{MPa}$, has a $\mathrm{M}$ strain of $7.8 \%$ during the first cycle (see Figure 5). When a SMA wire with a low dislocation density is cycled, its $\mathbf{M}$ strain decreases with an increasing number of cycles. This trend is observed in the three SMAs heat treated at $600^{\circ} \mathrm{C}$ (see Figures 5, 6, and 7). Considerable creep occurs in the SMA wires heat treated at $600^{\circ} \mathrm{C}$, and the creep rate of the wire is greatest at the start of cycling. The $\mathbf{M}$ strain at the start of cycling is attributed to the combined influences of low dislocation density and the large amount of creep that occurs. As the wire is cycled, the density of dislocations increases, the creep rate decreases, the active length of the wire increases, and the applied stress increases. All of these factors

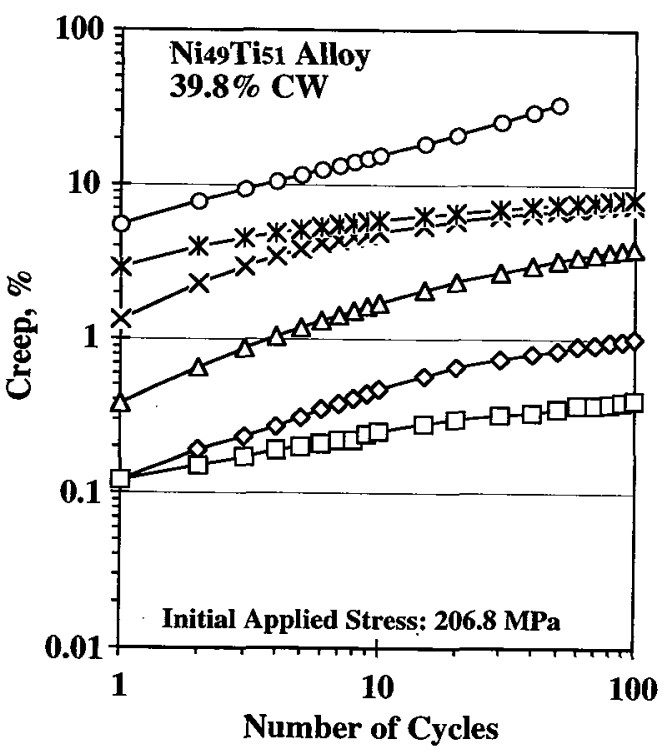

Figure 2: Creep properties of Ni49Ti51 alloy.

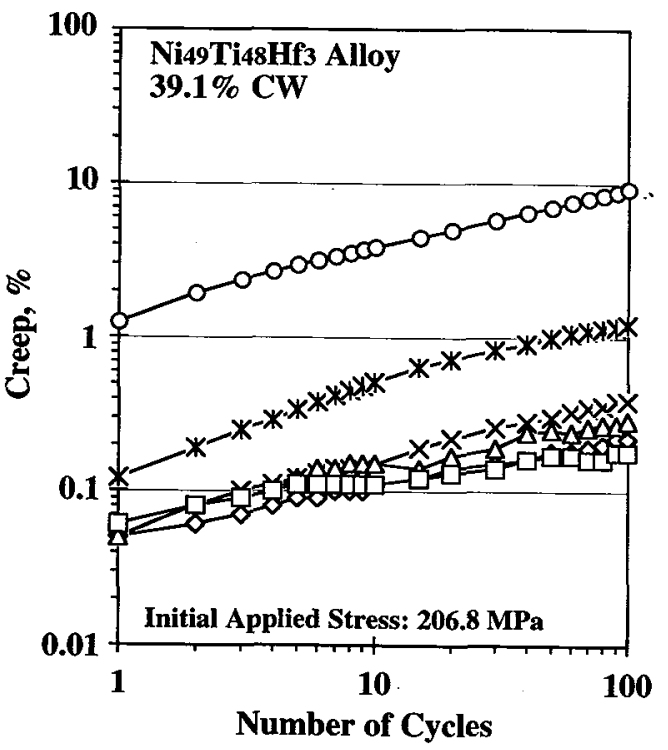

Heat Treatment Temperatures of SMA Wires

$$
\begin{aligned}
& -600^{\circ} \mathrm{C} \\
& -\times-500^{\circ} \mathrm{C} \\
& -\times-450^{\circ} \mathrm{C} \\
& -\triangle 400^{\circ} \mathrm{C} \\
& -\triangle 350^{\circ} \mathrm{C} \\
& -\square-300^{\circ} \mathrm{C}
\end{aligned}
$$

Permanent change in length

$$
\text { Creep }=\frac{\text { of wire in austenite phase }}{\text { Starting length of wire in }} \times 100
$$

Figure 4: Creep properties of Ni49Ti48Hf3 alloy. 
influence $\mathbf{M}$ strain. The influence of creep on $\mathbf{M}$ strain becomes less with increasing number of cycles and results in a decrease in $\mathbf{M}$ strain. Like creep, $\mathbf{M}$ strain is influenced by the substitution of Hf for Ti. A comparison of Figures 5, 6, and 7 indicates that the creep dependence of $\mathbf{M}$ strain is suppressed with the presence of $\mathrm{Hf}$. The alloy with 3 at.\% $\mathrm{Hf}$ exhibits constant $\mathbf{M}$ strain during cycling for HT temperatures below $600^{\circ} \mathrm{C}$. The SMA without Hf shows significant deviation from the constant strain behavior when heat treated above $350^{\circ} \mathrm{C}$. The low M strain in the alloys containing Hf is due in part to the lesser amount of creep in the Hf containing SMAs, especially when heat treated at high temperatures. Lower $\mathbf{M}$ strain in the Hf containing SMAs is also attributed to the lattice distortion caused by the size difference between Hf and $\mathrm{Ti}$, and to Hf-Ti and Hf-Ni electronic interactions, which alter the interaction of dislocations in the lattice.

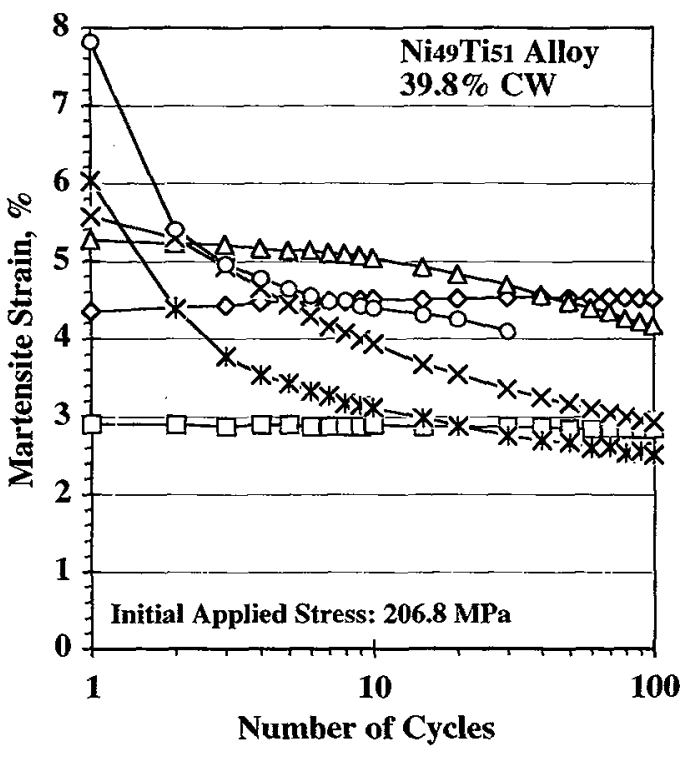

Figure 5: Martensite strain of Ni49Ti51 alloy.

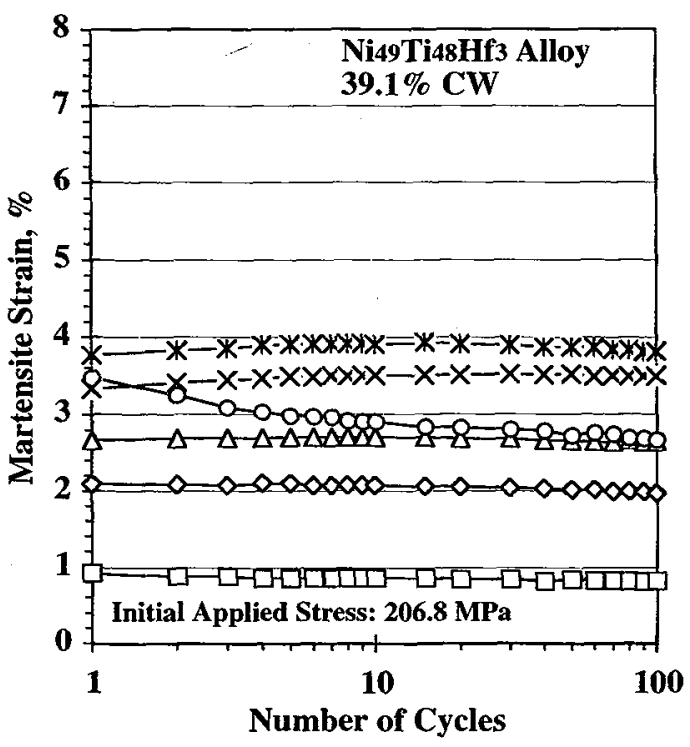

Figure 7: Martensite strain of Ni49Ti48Hf3 alloy.

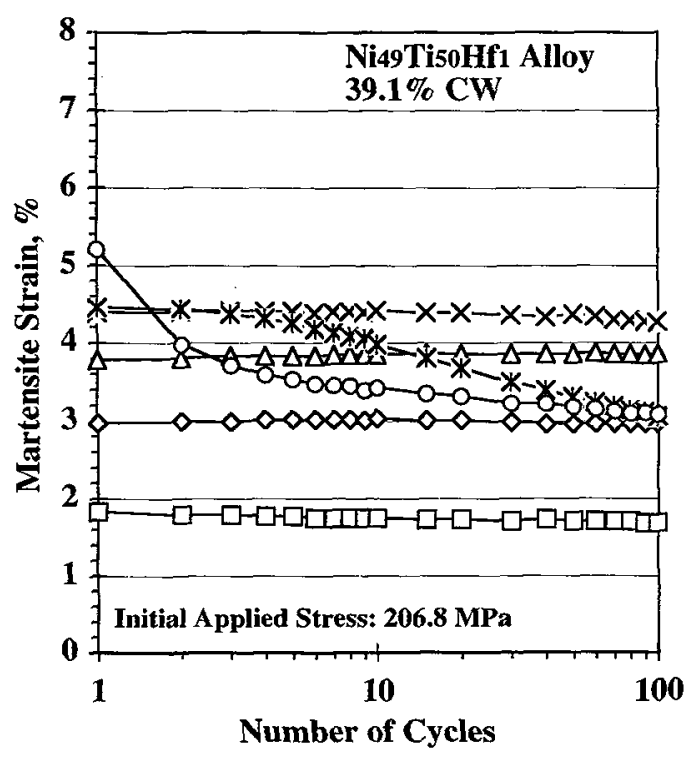

Figure 6: Martensite strain of Ni49Ti50Hfl alloy.

\section{Heat Treatment Temperatures of SMA Wires}

$$
\begin{aligned}
& -0-600^{\circ} \mathrm{C} \\
& -x-500^{\circ} \mathrm{C} \\
& -x-450^{\circ} \mathrm{C} \\
& -\triangle-400^{\circ} \mathrm{C} \\
& -\sigma-350^{\circ} \mathrm{C} \\
& -\square-300^{\circ} \mathrm{C}
\end{aligned}
$$

$$
\frac{\begin{array}{c}
\text { Length of wire in } \\
\text { martensite phase } \\
\text { during a specific } \\
\text { cycle }
\end{array}}{\begin{array}{c}
\text { Length of wire in } \\
\text { austenite phase at } \\
\text { beginning of a } \\
\text { specific cycle }
\end{array}}
$$$$
\underset{\text { strain }}{\text { Martensite }}=\frac{\text { cycle }}{\text { Length of wire in }} \times 100
$$ 


\section{SUMMARY}

The results of this investigation show that creep and $\mathbf{M}$ strain of NiTi based SMAs are influenced by HT temperature, $\mathrm{Hf}$ content, and transformation cycling. These results are summarized as follows:

- Creep in Ni49Ti51, Ni49Ti5oHf1, and Ni49Ti48Hf3 wires increases with an increasing number of cycles.

- For a specific composition and a specific number of transformation cycles, creep generally increases with increasing $\mathrm{HT}$ temperature.

- For a specific number of transformation cycles and a specific HT temperature, creep increases with decreasing Hf content.

- For the Ni49Ti51, Ni49Ti5oHf 1 , and Ni49Ti48Hf3 wires, heat treated at high temperatures $\left(600^{\circ} \mathrm{C}\right), \mathbf{M}$ strain decreases with an increasing number of transformation cycles.

- When heat treated at high temperatures, the greatest decrease in $\mathbf{M}$ strain during cycling occurs in the binary NiTi alloy, and the least decrease in M strain occurs in the NiTi based alloy with 3 at.\% Hf.

- When heat treated at low temperatures, there is little change in $\mathbf{M}$ strain when the SMAs are cycled.

- At the start of cycling, the M strain of the SMAs generally increases with increasing HT temperature.

- At the start of cycling for a specific HT, $M$ strain decreases with increasing Hf content.

\section{Acknowledgments}

The authors are grateful for the technical assistance given by Steven A. Linstead of Johnson Controls, Inc. in preparing the NiTiHf alloys, and for the financial assistance provided by Johnson Controls, Inc. and the National Science Foundation/Alabama EPSCoR Program.

\section{References}

[1] Kleinherenbrink P.M. and Beyer J., "Control of the transformation temperatures of TiNi shape memory alloys by ternary additions", European Conference on Martensitic Transformation in Science and Technology, Bochum, Germany 1989, E. Hornbogen and N. Jost Eds. (DGM Informationsgesellschaft m.b.H., Oberursel, Germany, 1989) pp. 187-190.

[2] AbuJudom D.N., Thoma P.E., Kao M., and Angst D.R., U.S. Patent \# 5,114,504, 1992.

[3] Angst D.R., Thoma P.E., and Kao M.Y.," "The effect of hafnium content on the transformation temperatures of Ni49Ti51-XHfX shape memory alloys", International Conference on Martensitic Transformátions (ICOMAT-95), Lausanne, Switzerland 20-25 August 1995, R. Gotthardt and J. Van Humbeeck Eds. (Les Editions de Physique, Les Ulis, France, 1995) pp. C8-747-752.

[4] Mulder J.H., Beyer J., Donner P., and Peterseim J., "On the high temperature shape memory capabilities of Ni-(TiZr) and Ni-(TiHf) alloys", First International Conference on Shape Memory and Superelastic Technologies (SMST-94), Pacific Grove, CA 7-10 March 1994, A.R. Pelton, D. Hodgson, and T. Duerig Eds. (MIÄS, Monterey, CA, 1995) pp. 55-60.

[5] Mulder J.H., "Investigation of high temperature shape memory alloys from the Ni-Ti-Zr and Ni-Ti-Hf systems", PhD. Thesis, University of Twente, Enschede, The Netherlands, 1995.

[6] Tuominen S.M., "High transformation temperature Ni-Ti-Hf alloys", First International Conference on Shape Memory and Superelastic Technologies (SMST-94), Pacific Grove, CA 7-10 March 1994, A.R. Pelton, D. Hodgson, and T. Duerig Eds. (MIAS, Monterey, CA, 1995) pp. 49-54.

[7] Russell S.M. and Sczerzenie F., "Engineering considerations in the application of Ni-Ti-Hf and NiAl as practical high-temperature shape memory alloys", First International Conference on Shape Memory and Superelastic Technologies (SMST-94), Pacific Grove, CA 7-10 March 1994, A.R. Pelton, D. Hodgson, and T. Duerig Eds. (MIAS, Monterey, CA, 1995) pp. 43-48.

[8] Zhang C., Zee R., and Thoma P.E., "Influcnce of thermal-mechanical processing on martensitic transformation of NiTi and NiTiHf shape memory alloys", International Conference on Displasive Phase Transformations and their Applications in Materials Engineering, Urbana, IL 8-9 May 1996: To be published in conference proceedings.

[9] Zhang C., Thoma P.E., and Zee R.H., "The influence of hafnium content, cold work, and heat treatment on the R-phase transformation of NiTi based shape memory alloys", Materials for Smart Systems II (MRS Vol. 459) Boston, MA 2-5 December 1996, E. George; R. Gotthardt, K. Otsuka, S. Trolier-McKinstry, and M. Wun-Fogle Eds. (Materials Research Society, Pittsburgh, PA, 1997) pp. 281-286.

[10] Zhang C., "Influence of thermal-mechanical processing on NiTi based shape memory alloys", Master of Science Thesis, Auburn University, Auburn, AL, 1996.

[11] Thoma P.E., Blok A.M. and Kao M.Y., "Pushing the limit to achieve NiTi SMA actuating members that are dimensionally stable and have high transformation temperatures", Shape-Memory Materials and Phenomena-Fundamental Aspects and Applications (MRS Vol. 246) Boston, MA 3-5 December 1991, C. Liu, H. Kunsmann, K. Otsuka, M. Wuttig Eds. (Materials Research Society, Pittsburgh, PA, 1992) pp. 321330 . 